\title{
Percepção de discentes de farmácia e enfermagem de uma instituição de ensino superior sobre a utilização de psicofármacos na gestação
}

\author{
Pharmacy students perception and nursing of a higher education institution on the use \\ in pregnancy psychotropics
}

\author{
Karla Bruna Nogueira Torres Barros ${ }^{1 *}$, Sandna Larissa Freitas dos Santos², Gláucia Posso Lima ${ }^{3}$ \\ ${ }^{1}$ Mestre em Ensino na Saúde, Universidade Estadual do Ceará, Professora do Curso de Farmácia do Centro \\ Universitário Católico de Quixadá, CE; ${ }^{2}$ Farmacêutica pelo Centro Universitário Católica de Quixadá, CE; ${ }^{3}$ Doutora em \\ Saúde Coletiva, Universidade Estadual do Ceará
}

\begin{abstract}
Resumo
Introdução: o ensino nas instituições de ensino superior restringe o assunto abordado quanto à utilização de psicofármacos para sofrimentos psíquicos junto ao aluno, direcionando a aprendizagem ao tratamento específico de problemas mentais. Objetivo: Compreender a formação, conhecimento e percepção dos graduandos dos cursos de farmácia e enfermagem do Centro Universitário Católica de Quixadá-CE, sobre a utilização de psicofármacos na gestação. Metodologia: caráter predominantemente quantitativo e transversal, realizado com 59 discentes de uma instituição de ensino superior, nos cursos de Farmácia e Enfermagem dos dois últimos períodos da graduação. Para tanto, utilizou-se um questionário semiestruturado para a coleta de dados juntamente com uma análise documental. Resultados: verificou-se quanto à formação, um número insatisfatório de disciplinas elencadas com o assunto psicofármacos (5\%). Em relação ao conhecimento e percepção dos discentes quanto ao assunto psicofármacos e efeitos negativos em gestantes, observou-se uma grande deficiência: $(77 \%)$ relataram não conhecer os efeitos teratogênicos causados por estes. A análise revelou a necessidade que os graduandos de saúde apresentam frente à realidade prática. Como subsídio e feedback para estes alunos, foi apresentado à coordenação dos cursos uma proposta de curso optativo estruturado de metodologias ativas, e os coordenadores mostraram-se muito interessados, a ponto de repensarem em uma mudança matricial. Conclusão: acredita-se que o reconhecimento da importância e da necessidade da formação como prática transversal nos cursos de graduação em Saúde, poderá contribuir para o crescimento profissional e pessoal enquanto estudantes e colaboradores de qualidade de vida, enquanto profissionais. Palavras-chave: Educação. Conhecimento. Psicotrópicos. Gravidez.
\end{abstract}

\begin{abstract}
Introduction: teaching in higher education institutions restricts the subject of the use of psychotropic drugs for psychic suffering to the student, directing learning to the specific treatment of mental problems. Objective: to understand the training, knowledge and perception of the undergraduate students of the pharmacy and nursing courses of the Catholic University Center of Quixadá-CE, on the use of psychoactive drugs during pregnancy. Methodology: a predominantly quantitative and transversal character, performed with 59 students from an institution of higher education, in the Pharmacy and Nursing courses of the last two graduation periods. For this purpose, a semi-structured questionnaire was used for the collection of data together with a documentary analysis. Results: there was an unsatisfactory number of disciplines related to the subject of psychotropic drugs (5\%). Regarding the knowledge and perception of the students about the subject of psychoactive drugs and negative effects on pregnant women, a great deficiency was observed: (77\%) reported not knowing the teratogenic effects caused by them. The analysis revealed the need for health graduates to face practical reality. As a subsidy and feedback for these students, a proposal for a structured optional course of active methodologies was presented to the coordination of the courses, and the coordinators were very interested, to the point of rethinking a matrix change. Conclusion: it is believed that the recognition of the importance and necessity of training as a transversal practice in undergraduate courses in Health, can contribute to professional and personal growth as students and quality-of-life professionals as professionals. Keywords: Education. Knowledge. Psychotropics. Pregnancy.
\end{abstract}

\section{INTRODUÇÃO}

A formação em saúde no Brasil, com ênfase na área médica, foi fortemente influenciada pela reforma educacional promovida por Flexner, na década de 1960, caracterizada pelo reconhecimento do atendimento hospitalar e pelo modelo biomédico. Contudo, modelos e reformas

Correspondente/Corrsponding: *Karla Bruna Nogueira Torres BarrosEnd: Rua 05, 90 - Planalto Renascer, Quixadá - CE, CEP: 63901-220. - Tel: (88) 3412-6700. - E-mail: karlabruna1@hotmail.com educacionais propostas não atendem às necessidades de formação de profissionais de saúde, conectados com a realidade vivenciada. Observa-se o despreparo dos profissionais recém-formados para atuarem na prática clínica, que é um modelo complexo, inerente ao sistema público ou privado de saúde, pois apresentam métodos peculiares que deveriam ser realizados por profissionais habilitados e que tivessem recebido formação adequada (PAGLIOSA; DA RÓS, 2008). 
As diretrizes curriculares nacionais dos cursos da área da saúde reiteram a necessidade de a formação superior propiciar competências e habilidades para o trabalho em equipe multiprofissional, com a finalidade de garantir a integralidade das ações em todos os níveis de atenção, dando ênfase à problematização e às vivências preparando o profissional com um perfil distanciado do tecnicismo (BRASIL, 2012a).

O uso de medicamentos na gravidez merece especial atenção, pelos riscos potenciais que o feto em desenvolvimento é exposto, devendo sempre ser considerado o risco e benefício, devendo a princípio, ser evitado (ROCHA et al., 2013). Considera-se que a palavra risco tem várias conotações semânticas - perigo, probabilidade, incerteza, chance - e seu emprego, usualmente, perpassa todas elas. Em outro sentido pode ser explicado, como a probabilidade de ocorrência de um efeito adverso em uma população, dadas as condições particulares de exposição (MOREIRA et al., 2014).

A tragédia que teve um marco histórico foi a da talidomida na década de 1960, onde marcou o início de um tempo de reflexão e de especial atenção da prática médica sobre o uso de medicamentos na gestação. Estudos clínicos têm, desde então, auxiliado a esclarecer muitos pontos obscuros relacionados à terapêutica medicamentosa na gravidez. Poucos, entretanto, têm sido conduzidos no âmbito da avaliação do uso de medicamentos durante a gestação, demonstrando assim, a necessidade de profissionais com uma formação adequada e intensa sobre o assunto, para assim, serem realizadas as devida intervenções (FONSECA, 2012).

No Brasil ainda são escassos estudos que avaliam os riscos potenciais relacionados à teratogenicidade no período gestacional, embora, muitas evidências já tenham sido descritas e comprovadas, haja visto que as experiências e estudos de caso, são hoje a principal forma de afirmar e agregar conhecimento à população e profissionais de saúde (FINKLER; CAETANO; RAMOS, 2013).

Os psicofármacos, em especial alguns anticonvulsivantes, apresentam efeitos teratogênicos potencialmente perigosos na formação do feto. Estes, quando utilizados durante a gravidez podem determinar como efeito teratogênico: alterações múltiplas, destacando-se o comprometimento dos ossos craniofaciais, a trigonocefalia, ausência de palato, lábio leporino, dentre outros. É recomendável evitar sua utilização e, na impossibilidade, administrá-lo na menor dose possível (MOREIRA et al., 2014).

O ensino nas instituições de ensino superior, parece estar restringindo o assunto abordado junto ao aluno, direcionando a aprendizagem ao tratamento específico de problemas mentais, ou seja, à utilização de psicofármacos para sofrimentos psíquicos diagnosticados em pacientes adultos que apresentam distúrbios, esquecendo de associar a grupos com perfil vulnerável como: gestantes, idosos e crianças. Surge então, a preocupação com os discentes que estarão diretamente lidando com pacientes de grupos diferenciados, (gestantes, crianças e idosos) fazendo-se necessário conhecer o perfil destes, e buscar aperfeiçoar a prática acadêmica, para que os estudantes tenham uma base de conhecimento adequada nos espaços de atuação. A escolha dos dois últimos períodos do curso torna-se relevante a partir do pressuposto que os acadêmicos tenham concluído e vivenciado um maior número de disciplinas (RODRIGUES; MANTOVANI, 2007).

O presente estudo visa conhecer a formação e percepção dos graduandos dos cursos de farmácia e enfermagem do Centro Universitário Católica de Quixadá-CE (Unicatólica) sobre a utilização de psicofármacos na gestação, inicialmente conhecendo as dificuldades apresentadas por alunos concludentes, a fim de colaborar com o crescimento mútuo.

\section{METODOLOGIA}

O presente estudo foi realizado de forma transversal, analítico, consistindo em uma análise de caso situacional, predominantemente quantitativo. Foi realizado com os discentes do curso de Farmácia e Enfermagem dos dois últimos períodos da graduação, e desenvolvido no Centro Universitário Católica de Quixadá, no período de agosto a outubro de 2015. A referida instituição dispõe de 17 cursos, onde 6 (biomedicina, educação física, enfermagem, farmácia, fisioterapia e odontologia) são da área da saúde. O curso de farmácia é composto por 10 períodos, totalizando 5 anos de graduação, apresenta atualmente 209 alunos matriculados regularmente em todo o curso, onde destes 27 compõem o $9^{\circ}$ e $10^{\circ}$ período. Já o curso de enfermagem se divide em 9 períodos com total de 4 anos e 6 meses, totalizando 358 alunos em todo o curso, destes, 43 correspondem ao $8^{\circ}$ e $9^{\circ}$ período.

Foram realizadas duas técnicas para coleta de dados, a documental, que consistiu na identificação dos conteúdos e programas existentes na graduação, através das ementas relacionadas, e através da entrevista (Aplicação do questionário) que averiguou a percepção e conhecimento dos discentes sobre psicofármacos em gestantes, bem como também identificou suas principais dúvidas.

Participaram 59 acadêmicos, 25 do curso de Farmácia e 34 do curso de Enfermagem, regularmente matriculados, fornecida pelas coordenações dos cursos, que disponibilizaram as listas após terem lido a carta de explicitação. Foram inclusos todos os graduandos matriculados que compareceram ao local marcado pelo pesquisador, mediante o aceite e assinatura do termo de Consentimento Livre e Esclarecido, e procedeu-se com a aplicação de um questionário com perguntas semiestruturadas.

Os resultados foram analisados por meio de distribuição de frequência simples (n) e relativa (\%), em que apenas a variável idade foi analisada utilizando média, desvio-padrão e Coeficiente de Variação (CV\%). Com esse último, verifica-se que o grupo apresenta homogeneidade em relação a variável idade (CV abaixo de 30\%). Para a análise das respostas por curso, utilizou-se o cruzamento das variáveis e que se verificou a significância por meio do 
teste do Qui-quadrado $\left(\chi^{2}\right)$ e, quando adequado, o teste Exato de Fisher. Para essas análises, utilizou-se o programa Statistical Package for the Social Sciences (SPSS) 22.0.

$\mathrm{O}$ presente projeto de pesquisa buscou respeitar as diretrizes e normas que regulamentam as pesquisas envolvendo seres humanos dispostas na Resolução 466/12 do Conselho Nacional de Saúde - CNS (BRASIL, 2012b), foi encaminhado para apreciação pelo Comitê de Ética e Pesquisa (CEP) do Centro Universitário Católica de Quixadá, através da Plataforma Brasil, este emitiu o parecer de aprovação sob número 756.183 , garantindo aos participantes o sigilo e anonimato das informações dadas, onde estas serão utilizadas somente para os fins previstos na pesquisa.

\section{RESULTADOS}

No período da pesquisa, o curso de Enfermagem contava com um total de 43 alunos matriculados entre o $8^{\circ}$ e $9^{\circ}$ período, e o curso de Farmácia com 27 alunos cursando $09^{\circ}$ e $10^{\circ}$ período. Responderam o questionário $34 / 43(79,1 \%)$ alunos do curso de Enfermagem e $25 / 27$ $(92,5 \%)$ do curso de Farmácia, totalizando 59/70 discentes respondentes, correspondendo a $84,2 \%$ do número de alunos matriculados nos dois cursos. Destes 23 (39\%) cursavam o 8 o semestre, $26(45,8 \%)$ o 9o semestre, e 9 $(15,3 \%)$ o 10 o semestre.

Tabela 1 - Características dos estudantes dos cursos de Farmácia e Enfermagem da Unicatólica de Quixadá-CE, Nordeste, Brasil, 2015.

\begin{tabular}{|c|c|c|c|}
\hline Variável & Categoria & $\mathbf{N}$ & $\%$ \\
\hline \multirow[t]{3}{*}{ Curso } & Farmácia ( $N=27)$ & 25 & 42,4 \\
\hline & Enfermagem $(\mathrm{N}=43)$ & 34 & 57,6 \\
\hline & Total & 59 & 100,0 \\
\hline \multirow[t]{4}{*}{ Semestre } & $1-80$ & 23 & 39,0 \\
\hline & $2-90$ & 27 & 45,8 \\
\hline & $3-100$ & 9 & 15,3 \\
\hline & Total & 59 & 100,0 \\
\hline \multirow[t]{3}{*}{ Sexo } & 1 - Masculino & 18 & 30,5 \\
\hline & 2 - Feminino & 41 & 69,5 \\
\hline & Total & 59 & 100,0 \\
\hline \multirow[t]{3}{*}{ Estado civil } & 1 - Solteiro (a) & 46 & 78,0 \\
\hline & 2 - Casado (a) & 13 & 22,0 \\
\hline & Total & 59 & 100,0 \\
\hline \multirow[t]{2}{*}{ Idade } & Mínimo - 20 anos & Média & CV \\
\hline & Máximo - 33 anos & $23,90( \pm 2,68)$ & $11,21 \%$ \\
\hline
\end{tabular}

Fonte: Autoria própria.

Considerando uma margem de erro de $5 \%$, nível de confiança de $95 \%$ e nível de heterogeneidade de $50 \%$, onde dos 70 alunos matriculados na instituição de pesquisa, 59 participaram ativamente, e apenas 11 não compareceram ao local da aplicação do questionário.

A justificativa da escolha de discentes dos dois últimos períodos de cada curso, foi por conta da predominância de disciplinas finalizadas por estes, resultando assim, em um maior conhecimento geral e específico quanto aos assuntos abordados na área de saúde. $\mathrm{A}$ idade dos entrevistados variou de, no mínimo 20 e, no máximo, 33 anos, prevalecendo com $87 \%$ de 22 a 26 anos e média de 23,90 anos $( \pm 2,68)$ e Coeficiente de Variação de $11,21 \%$, que indica que o grupo participante da pesquisa é homogêneo em relação à idade.

Quando questionados, se no percurso da graduação, foi lecionado nas disciplinas, sobre psicofármaco ou medicamentos de controle especial foi verificado que $96,6 \%$ alunos responderam que sim e $3,4 \%$ responderam nunca ter visto este assunto. Aos que afirmaram de forma positiva, $41(69,5 \%)$ responderam que esta abordagem estava na Farmacologia aplicada (Tabela 2).

Tabela 2 - Disciplinas que abordaram o assunto "psicofármaco" ou "medicamentos de controle especial" de acordo com os estudantes dos cursos de Farmácia e Enfermagem da Unicatólica de Quixadá-CE, Nordeste, Brasil, 2015.

\begin{tabular}{l|c|c}
\hline & Frequência & Porcentagem (\%) \\
\hline Farmacoepidemiologia & 7 & 11,9 \\
Prática I a IV & 7 & 11,9 \\
Saúde mental & 15 & 25,4 \\
Farmacologia aplicada & 41 & 69,5 \\
Outros (Saúde da mulher, deonto- & 3 & 5,1 \\
logia, Estágio) & & \\
\hline
\end{tabular}

Fonte: Autoria própria.

Observando as ementas e programas de curso disponibilizados pela coordenação dos cursos envolvidos, observou-se que apenas cinco disciplinas (dois de farmácia) e (três de enfermagem) (Tabela 3) apresentaram o conteúdo psicofármacos diluído em meio a outros assuntos, e apenas um deste, tinha associação com grupo específico (idosos).

Tabela 3 - Distribuição de disciplinas encontradas nas ementas e programas de curso, contendo o assunto psicofármaco nos cursos de Farmácia e Enfermagem da Unicatólica de Quixadá-CE, Nordeste, Brasil, 2015.

\begin{tabular}{l|l}
\hline FARMÁCIA & ENFERMAGEM \\
\hline Farmacoepidemiologia e Farmacovigilancia & Farmacologia \\
\hline \multirow{2}{*}{ Farmacologia } & Saúde Mental \\
\cline { 2 - 2 } & Saúde Coletiva \\
\hline
\end{tabular}

Fonte: Autoria própria.

As disciplinas citadas pelos alunos estão condizentes com as que apresentaram ementas descrevendo o assunto abordado, com exceção de Prática IV, que foi especificada por três discentes; e a disciplina de Saúde coletiva, que apresentou a descrição do conteúdo nas ementas, mas não foi relatada por nenhum dos estudantes.

Os alunos lembraram-se de aulas com o assunto psicofármaco e descreveram as disciplinas acima relatadas; dos 57 alunos que responderam "sim" em relação à 
oferta do assunto, $41(69,5 \%)$ apontaram a disciplina de Farmacologia, $15(25,4 \%)$ citaram a disciplina de Saúde Mental, 7 (11,9\%) a Farmacoepidemiologia e 7 (11,9\%) alguma disciplina de Prática (I a IV). Observamos que alguns citaram mais de uma disciplina em suas respostas. Estes valores correspondem a 79,6\% da amostra total, pois $20,4 \%$ não citaram nenhuma disciplina, isso reflete uma deficiência na exploração do assunto abordado frente às pouquíssimas disciplinas relatadas, e a dificuldade dos alunos em tornar a aprendizagem significativa.

Quando interrogado aos participantes se o conteúdo psicofármacos fora associado a algum público alvo, 32 $(54,2 \%)$ afirmaram que o assunto foi repassado rápido e não houve nenhuma associação, 19 (32,2\%) relataram ter estudado o assunto relacionado a gestantes, $11(18,6 \%)$ a crianças e $18(30,5 \%)$ a idosos.

No requisito autopercepção de aprendizagem sobre o assunto fármacos, os discentes consideraram em grande maioria $(62,7 \%)$, terem tido as informações suficientes, sendo esta descrita como boa por $84 \%$ da Farmácia e $47,1 \%$ da Enfermagem, e apenas uma pequena amostra, considerou-se como um ótimo aprendiz. Observamos que ocorreu uma diferença significativa no cruzamento das respostas por curso, visto que os alunos da Farmácia tiveram uma maior autopercepção positiva em comparação aos alunos da Enfermagem $\left(\chi^{2}=14,439\right.$ para $p=$ 0,001, Tabela 4).

Tabela 4 - Autopercepção de aprendizagem sobre assunto dos estudantes dos cursos de Farmácia e Enfermagem da Unicatólica de Quixadá-CE, Nordeste, Brasil, 2015.

\begin{tabular}{|c|c|c|c|c|}
\hline & \multicolumn{2}{|c|}{ Curso } & \multirow{2}{*}{ Total } \\
\hline & & Farmácia & Enfermagem & \\
\hline \multirow{6}{*}{$\begin{array}{l}\text { Como você considera } \\
\text { sua aprendizagem em } \\
\text { relação a este assunto* } \\
{ }^{*} \chi^{2}=14,439 \text { para } p= \\
0,001\end{array}$} & \multirow{2}{*}{ Ruim } & 2 & 18 & 20 \\
\hline & & $8,0 \%$ & $52,9 \%$ & $33,9 \%$ \\
\hline & \multirow{2}{*}{ Boa } & 21 & 16 & 37 \\
\hline & & $84,0 \%$ & $47,1 \%$ & $62,7 \%$ \\
\hline & \multirow{2}{*}{ Ótima } & 2 & 0 & 2 \\
\hline & & $8,0 \%$ & $0,0 \%$ & $3,4 \%$ \\
\hline \multirow{2}{*}{\multicolumn{2}{|c|}{ Total }} & 25 & 34 & 59 \\
\hline & & $100,0 \%$ & $100,0 \%$ & $100,0 \%$ \\
\hline
\end{tabular}

Fonte: Autoria própria

O conhecimento específico dos efeitos negativos causados por psicofármacos mostrou-se conhecido por parte dos alunos, no total $63,8 \%$ destes afirmaram conhecer os potenciais efeitos que estes podem causar em fetos durante a gestação. Do curso de Farmácia, $76 \%$ alunos responderam sim e 54,5\% do curso de Enfermagem, também conhecem os mesmos, sendo essa diferença não significativa (Tabela 5).
Tabela 5 - Indicadores de conhecimento sobre influência de psicofármacos na gravidez pelos estudantes dos cursos de Farmácia e Enfermagem da Unicatólica de Quixadá-CE, Nordeste, Brasil, 2015.

\begin{tabular}{|c|c|c|c|c|}
\hline & & \multicolumn{2}{|c|}{ Curso } & \multirow{2}{*}{ Total } \\
\hline & & Farmácia & Enfermagem & \\
\hline \multirow{4}{*}{$\begin{array}{l}\text { Alguns psicofármacos in- } \\
\text { fluenciam negativamente } \\
\text { o feto durante a exposição } \\
\text { na gravidez, você já estu- } \\
\text { dou sobre isso }\end{array}$} & \multirow{2}{*}{ Não } & 6 & 15 & 21 \\
\hline & & $24,0 \%$ & $45,5 \%$ & $36,2 \%$ \\
\hline & \multirow{2}{*}{ Sim } & 19 & 18 & 37 \\
\hline & & $76,0 \%$ & $54,5 \%$ & $63,8 \%$ \\
\hline \multirow{2}{*}{\multicolumn{2}{|c|}{ Total }} & 25 & 33 & 38 \\
\hline & & $100,0 \%$ & $100,0 \%$ & $100,0 \%$ \\
\hline
\end{tabular}

$* \chi^{2}=2,835$ para $p=0,092$.

Fonte: Elaborada pela autora.

Quanto aos principais danos causados ao feto durante a exposição na gestação, foi solicitado que os alunos assinalassem aqueles no qual conheciam como consequentes. Durante a abordagem notou-se uma dificuldade na escolha do item, onde alguns dos discentes, não sabiam sequer a definição patológica ali estabelecida. A expressão da opinião foi empírica e esporádica, havendo uma grande diferença entre os cursos, sendo Lábio leporino $(28,8 \%)$ e Fenda palatina (32,2\%) (Tabela 6) e, exceto (diminuição) Apgar, todos os outros tiveram diferenças significativas nas respostas, seja no Teste do Qui-quadrado, seja no Exato de Fisher.

Tabela 6 - Conhecimento dos discentes sobre efeitos de fármacos nos cursos de Farmácia e Enfermagem da Unicatólica de Quixadá-CE, Nordeste, Brasil, 2015.

\begin{tabular}{l|r|r|c|r|r|c}
\hline \multicolumn{1}{c}{} & \multicolumn{2}{c}{ Farmácia } & \multicolumn{2}{c}{ Enfermagem } & \multicolumn{2}{c}{ Total } \\
\cline { 2 - 7 } & \multicolumn{1}{c|}{$\mathrm{N}$} & \multicolumn{1}{c}{$\%$} & $\mathrm{~N}$ & \multicolumn{1}{c}{$\%$} & $\mathrm{~N}$ & $\%$ \\
\hline (Aumento) Bilirrubina** & 0 & 0 & 6 & $17,6 \%$ & 6 & 10,2 \\
Lábio leporino** & 12 & $48 \%$ & 5 & $14,7 \%$ & 17 & 28,8 \\
Fenda palatina* & 16 & $64 \%$ & 3 & $8,3 \%$ & 19 & 32,2 \\
(Diminuição) Apgar & 1 & $4 \%$ & 6 & $17,6 \%$ & 7 & 11,9 \\
Espinha bífida* & 9 & $36 \%$ & 4 & $11,8 \%$ & 13 & 22,0 \\
Genitália ambígua** & 7 & $28 \%$ & 1 & $2,9 \%$ & 8 & 13,6 \\
Atresia Anal** & 10 & $40 \%$ & 3 & $8,8 \%$ & 13 & 22,0 \\
\hline
\end{tabular}

Fonte: Elaborada pela autora.

* significativa para p menor que 0,05 no Teste Exato de Fisher.

**significativa para p menor que 0,05 no Teste do Qui-quadrado.

Quando indagados se "Como profissional de Saúde, o discente sente-se apto a atuar e dar informações a gestantes em utilização de psicofármaco?", 40 (69\%) afirmaram não se sentirem seguros, retratando mais uma vez a necessidade de investimento na aprendizagem e 
percebe-se que isso foi prevalente em ambos os cursos, não havendo diferença significativa $\left(\chi^{2}=0,0190\right.$ para $p=$ 0,890 ), e evidenciando estatisticamente que ambos os cursos necessitam de mais oportunidades de aprendizagem desse conteúdo.

Após este primeiro questionamento foi solicitado que os discentes apresentassem os motivos para tal dificuldade, e os mesmos homogeneamente relataram: (1) conhecimento básico, (2) aprendizagem não satisfatória, (3) necessidade de aprofundar conhecimento, (4) falta de domínio, (5) informações insuficientes e outros.

Com um quantitativo de 55 alunos (96,5\%), o questionamento relacionado à necessidade de um maior conhecimento sobre psicofármacos, liderou o ranking da presente pesquisa, onde $96,9 \%$ dos acadêmicos de Enfermagem e $96 \%$ dos acadêmicos de Farmácia entrevistados expressaram a necessidade de conhecer melhor o relatado assunto, em que, novamente, não houve diferença significativa $\left(\chi^{2}=0,0190\right.$ para $\left.p=0,890\right)$ reforçando ainda mais a tese desse estudo de que há lacunas na formação sobre psicofármacos.

Quanto à sugestão de melhorias para o alcance da aprendizagem significativa sobre psicofármaco ser direcionada à instituição pesquisada, $55(88 \%)$ dos alunos comentaram, e sugeriram: (1) a realização de cursos voltados para o assunto, (2) uma maior abordagem por parte dos professores, (3) uma didática melhorada no ensino e (4) um maior número de disciplinas.

Em perguntas específicas a cada grupo distinto sobre sua atuação frente à prática com gestantes, os índices citados por eles não foram satisfatórios (Tabela 7).

Tabela 7 - Atuação enquanto profissional de Saúde dos discentes dos cursos de Farmácia e Enfermagem da Unicatólica de Quixadá-CE, Nordeste, Brasil, 2015.

No momento da dispensação de um psicofármaco à uma gestante, saberá informá-la sobre os riscos e efeitos negativos ou fazer intervenção medicamentosa? Por quê?

FARMACÊUTICO

$90 \%$ dos participantes responderam não, porque não se sentem capacitados.

No acompanhamento pré-natal com usuárias de psicofármacos, saberá tomar as devidas precauções? Por quê?

ENFERMEIRO

$88 \%$ dos participantes responderam não, porque não conhecem a farmacologias destes.

Fonte: Autoria própria.

Uma proposta para a criação de curso optativo foi apresentada aos coordenadores dos cursos de Farmácia e Enfermagem, na tentativa de ressignificação sobre o assunto abordado, onde o curso de Farmácia adotou a proposta para o semestre 2015.1 e o curso de Enfermagem ainda não deu parecer. Segue na (Tabela 8) a estrutura resumida curricular dos cursos.

Tabela 8 - Plano de aula do curso optativo apresentando aos coordenadores dos cursos de Farmácia e Enfermagem da Unicatólica de Quixadá-CE, Nordeste, Brasil, 2015.

\begin{tabular}{|c|c|c|c|c|c|c|}
\hline Disciplina: & \multicolumn{6}{|c|}{ Psicofármacos: Utilização em Grupos Especiais } \\
\hline Professor (a): & \multicolumn{6}{|c|}{ Karla Bruna Nogueira Torres Barros } \\
\hline Curso: & \multicolumn{2}{|l|}{ Farmácia/Enfermagem } & Semestre: & 2015.1 & Turma: & A e $B$ \\
\hline \multirow{2}{*}{$\begin{array}{l}\text { Unidade / Assuntos a Serem } \\
\text { Abordados }\end{array}$} & \multirow[b]{2}{*}{ Metodologia } & \multirow[b]{2}{*}{ Recursos } & \multicolumn{4}{|c|}{ DISTRIBUIÇÃO DAS ATIVIDADES } \\
\hline & & & $\begin{array}{l}\text { SEMANA ou } \\
\text { DIA }\end{array}$ & $\begin{array}{l}\text { AULAS } \\
\text { TEÓRICAS }\end{array}$ & $\begin{array}{l}\text { AULAS } \\
\text { PRÁTICAS }\end{array}$ & $\begin{array}{l}\text { ATIV. EXTRA } \\
\text { CLASSE }{ }^{(1)}\end{array}$ \\
\hline Apresentação da disciplina & $\begin{array}{l}\text { Demonstração da discipli- } \\
\text { na, entrega de plano de } \\
\text { ensino e cronograma }\end{array}$ & Quadro branco & 01 & 1 & - & $\begin{array}{c}1 \\
\text { Criação de } \\
\text { um Blog }\end{array}$ \\
\hline Conceito de Psicofármacos & Exposição oral dialogada & $\begin{array}{l}\text { Quadro branco e } \\
\text { data show }\end{array}$ & 02 & 1 & - & - \\
\hline Classificação de psicofármacos & Metodologias Ativas & Painel & 03 & 1 & - & - \\
\hline Psicofármacos em Gestantes & Metodologias Ativas & Mapa Conceitual & 04 & 1 & - & - \\
\hline $\begin{array}{l}\text { Estudo de caso de Psicofár- } \\
\text { macos }\end{array}$ & Metodologias Ativas & $\begin{array}{l}\text { Artigos } \\
\text { Arco de Marguerez }\end{array}$ & 05 & - & - & 1 \\
\hline $\begin{array}{l}\text { Efeitos Nocivos de Psicofár- } \\
\text { macos }\end{array}$ & Metodologias Ativas & $\begin{array}{l}\text { Quadro branco e } \\
\text { data show ou ar- } \\
\text { tigos }\end{array}$ & 06 & 1 & - & - \\
\hline Teratogenia & Exposição oral dialogada & Imagens artigos & 07 & 1 & - & - \\
\hline $\begin{array}{l}\text { Psicofármacos em Idosos e } \\
\text { Crianças }\end{array}$ & Metodologias Ativas & $\begin{array}{l}\text { Artigos } \\
\text { PBP }\end{array}$ & 08 & 1 & - & - \\
\hline $\begin{array}{l}\text { Farmacovigilância em psico- } \\
\text { fármacos }\end{array}$ & Metodologias Ativas & Circuito & 09 & 1 & 1 & - \\
\hline Avaliação & Auto - avaliação & Vídeos & 10 & 1 & - & - \\
\hline \multicolumn{4}{|l|}{ Total de horas integralizadas } & \multicolumn{3}{|l|}{60 horas } \\
\hline
\end{tabular}

Fonte: Autoria própria. 


\section{DISCUSSÃO}

Em um estudo semelhante aplicado por Seriano, Muniz e Carvalho (2013) no curso de Fisioterapia onde se pretendia verificar a percepção dos discentes quanto a sua formação para atuar no SUS, dos 54 alunos matriculados do $6^{\circ}$ ao $10^{\circ}$ período, 42 responderam ao questionário, correspondendo a $80,8 \%$ do universo da pesquisa. Os dados destes autores ainda corroboram com a presente pesquisa, onde a idade dos acadêmicos entrevistados variou de: no mínimo 18 e no máximo 28 anos, com média de $22,2( \pm 1,8)$ anos. Houve também uma maior predominância do sexo feminino com 30 entrevistados, correspondendo a $71,4 \%$.

No estudo de Dias, Lima e Teixeira (2013), relatou-se um maior número de instituições responsáveis pela formação de pessoal, constatando-se a extraordinária expansão do número de escolas e cursos na área de saúde, notadamente no setor privado, embora de forma desigual. No contexto dos cursos, observa-se o desencadeamento de reformas curriculares estimuladas pela aprovação da nova Lei de Diretrizes e Bases para a Educação que confere liberdade às instituições de ensino para o desenho de currículos inovadores, adequados às realidades regionais e às vocações das escolas, substituindo-se o antigo "currículo mínimo" pelas Diretrizes Curriculares Nacionais (DCN); mas ainda notoriamente alguns dos discentes não conseguem consolidar o conhecimento nas práxis.

Dias, Lima e Teixeira (2013) citam que a participação efetiva do aluno a qualquer evento desenvolvido na instituição é de fundamental importância, pois a formação de pessoal em saúde apresenta, como questão central, as limitações dos modelos de formação vigentes diante das demandas e necessidades decorrentes da construção do Sistema Único de Saúde (SUS) e da recomposição do setor privado, nas últimas décadas.

De acordo com as ementas e programas de curso disponibilizado pela coordenação dos cursos envolvidos, observou-se que apenas cinco disciplinas (dois de farmácia) e (três de enfermagem) apresentaram o conteúdo psicofármacos diluído em meio a outros assuntos, apenas um deste, tinha associação com grupo específico (idosos). Sabe-se que competências e habilidades são adquiridas durante todo o processo de graduação, e esta depende não só da abordagem de disciplinas, como de humanização e formação pessoal, crítica e reflexiva do ser humano como um todo (DIAS; LIMA; TEIXEIRA, 2013).

Para tanto, o tema "competências" tem se mostrado uma preocupação internacional, considerando o movimento da Galway Consensus Conference, realizada em 2008, em que representações de diversos países se reuniram para discutir o atual cenário de saúde e a necessidade de profissionais preparados para lidar com as novas demandas do setor (FRAGELLI; SHIMIZU, 2013).

Vaidergorn (2010) constatou em sua pesquisa, que temas revolucionários e impactantes ainda são pouco explorados nos campos de saúde coletiva, em nível nacional e desigualmente distribuído pelas unidades federativas, havendo necessidade de mais esforços por parte de gestores, por meio de maior incentivo a pesquisas, com vistas ao desenvolvimento profissional e do campo, ainda em construção e, consequentemente, para o fortalecimento do sistema público ou privado de saúde, onde estes estarão inseridos.

Quando o acadêmico se depara com a grande quantidade de informações disponíveis acerca de fármacos e terapias medicamentosas, é comum o desespero com o montante de informações necessárias para a prática profissional. Neste contexto, destaca-se o aprender, estudar, e a busca de informações qualificadas para subsidiar a tomada de decisão para a intervenção farmacêutica (GUIMARÃES, 2011).

Há uma comprovada importância em associar todos os tipos de fármacos com diferentes pacientes, principalmente com grupos que apresentam agravantes de risco, como por exemplo: em um levantamento em filhos de mães epilépticas que utilizam diariamente psicofármacos, estes apresentam risco duas vezes maior para malformações, tanto para anomalias maiores (lábio leporino, fenda palatina, defeitos cardíacos, malformações urogenitais, defeitos do tubo neural), quanto menores (hipo ou hipertelorismo, epicanto, distúrbios do crescimento nasal ou das orelhas, implantação baixa do cabelo, hipoplasia digital distal e das unhas). $O$ traço genético materno para epilepsia pode contribuir para este aumento de incidência de malformações (MOREIRA et al., 2014).

Moreira et al. (2014) em sua pesquisa afirmou que o uso de valproato de sódio (VS) como droga antiepiléptica durante a gravidez, pode determinar efeito teratogênico sobre as suturas cranianas do feto, resultando em cranioestenose e trigonocefalia devido ao fechamento precoce da sutura metópica, em mãe que utiliza VS associado a fenobarbital. É recomendável evitar sua utilização e, na impossibilidade, administrá-la na menor dose possível, com suplementação de ácido fólico. Esta informação deve ser repassada de forma concisa através de um profissional habilitado, por isso ressalta a importância na formação destes.

Evidencia-se a cada dia a busca por conhecimentos atualizados, e portanto, foi notório a curiosidade com que os entrevistados, despertando a cobrança de aprendizagem, onde muitos também relataram a negligencia de aproveitamento de algumas disciplinas, ao final, a investigação ao pesquisador foi corriqueira por parte de cada participante, onde este na maioria das vezes expos o assunto resumidamente, atendendo aquela demanda sedentária de saber. Percebeu-se assim, a preocupação dos sujeitos em contribuir com compromisso e responsabilidade, para o bem-estar da população, foi um momento de reflexão sobre a sua prática (RODRIGUES; MANTOVANI, 2007).

No estudo de Seriano, Muniz e Carvalho (2013) a percepção dos alunos quanto à sua formação para atuar no SUS, $43,3 \%$ consideraram, no último ano do curso estarem aptos, enquanto $56,7 \%$ dos alunos do 6 ㅇ ao 8 응 
período revelaram inaptidão para tal atuação. Os motivos relatados foram à falta de experiência e o conhecimento ainda insuficiente para o SUS, o que revela que mais esforços devem ser demandados para que as disciplinas possam assegurar a adequação dos alunos aos princípios e diretrizes do sistema de saúde vigente.

As vivências de situações de trabalho são pontos de partida para a busca de referenciais teóricos. Desde o primeiro ano de graduação, os estudantes deverão ser expostos ao "fazer", incentivados a assumirem responsabilidades e a realizarem intervenções de cuidado que superem a fragmentação dos atos profissionais. Então, parte da concepção de que as intervenções de cuidado não se restringem à aplicação de técnicas e procedimentos profissionais num "corpo adoecido", mas envolvem compreender o contexto, o universo cultural, os modos específicos de viver do usuário, e abrir possibilidades de diálogo com suas concepções, expectativas, prioridades e desejos, reconhecendo-o como sujeito na produção de sua própria saúde. Também demandam articulação de diferentes saberes e práticas e de serviços (CAPOZZOLO et al., 2013).

Cabe ressaltar a incorporação do uso de metodologias ativas no processo ensino-aprendizagem, estimulando-se o protagonismo dos estudantes, a responsabilidade com sua formação e o esforço de problematização das questões de saúde na contemporaneidade, particularmente a realidade brasileira, ancorado na utilização em larga escala de tecnologias de informações que conectam os alunos e docentes à sociedade de conhecimento, notadamente a Internet. Nessa perspectiva, o Projeto de Curso optativo que será implantado após análise desse estudo tenta desenvolver no aluno estas competências, a fim de encorajá-lo da melhor forma a adentrar no campo de trabalho. O indivíduo é o conjunto de seus Conhecimentos, Habilidades e Atitudes (CHA), ou seja, compreende as competências necessárias para que a pessoa desenvolva suas atribuições e responsabilidades usando a sua criatividade e inovação (GUIMARÃES, 2011).

Quando o aprendizado ocorre por meio de metodologias ativas, o conhecimento dos estudantes é comparável ao do método tradicional, porém, seu desempenho em relação às suas habilidades e atitudes é superior, reflexo da visão crítica proporcionada pelo método. Além disso, observa-se uma satisfação maior por parte dos acadêmicos quando são solicitados a avaliar o método, por considerarem que a utilização de casos práticos proporciona uma maior relação com a realidade, facilitando a fixação de conteúdos e promovendo o pensamento crítico (LIMBERGER, 2013).

As práticas baseadas em problemas exigem momentos de meditação para a melhoria da didática frente às dificuldades apresentadas, e constantes autoavaliação e replanejamento; além de habilidade comunicativa, exercício de liderança, e observação de aspectos referentes à interdisciplinaridade dos conteúdos envolvidos, a complexidade dos indivíduos, sujeitos dos casos, exigindo sensibilização, motivação e participação docente, discente e institucional. Não é um caminho fácil, mas, certamente, é recompensador, já que estudar passa a ser um ato desafiador e motivador (OLIVEIRA, 2010).

A instituição não se torna culpada por todas as lacunas observadas no conhecimento dos discentes, pois o que realmente precisa ser trabalhado são os currículos e ementas de cursos de todas as instituições formadoras de profissionais, independente do curso, inserindo informações necessárias ao cotidiano onde os egressos executarão suas práticas, outrora vivenciadas.

\section{CONCLUSÃO}

Ao trazer as interfaces do processo de conhecimentos sobre psicofármacos dos discentes dos cursos de Farmácia e Enfermagem do Centro Universitário Católica de Quixadá, concluiu-se que, quanto à formação, há uma necessidade de revisão das ementas e programas de curso, e também posteriormente uma aproximação entre o conteúdo proposto e prática de sala de aula, a fim de consolidar e estruturar o conhecimento a ser repassado para os acadêmicos.

A proposta do curso interativo optativo é pertinente diante dos variados aspectos desta pesquisa, as práticas baseadas em problemas subsidiarão momentos de reflexão para a melhoria da didática frente às dificuldades apresentadas e a ressignificação de conteúdos outrora estudados, considerando o campo de atuação. Profissionais formados dessa maneira, e que conhecem as políticas de saúde, frequentemente irão adquirir uma postura de compromisso com o sistema de saúde. Com isso, busca-se a mudança de um paradigma em relação ao estudante e ao processo de ensino/aprendizagem, sendo um desafio, porém, certamente, é recompensador, já que estudar passa a ser um ato motivador.

\section{REFERÊNCIAS}

BRASIL. Ministério da Saúde. Resolução no 466, de 12 de dezembro de 2012. Aprovar as seguintes diretrizes e normas regulamentadoras de pesquisas envolvendo seres humanos. Brasília, 2012a.

Ministério da Educação. Resumo técnico censo da educação superior 2010. Brasília, 2012b. Disponível em: <http://download.inep.gov. br/educacao_superior/censo_superior/resumo_tecnico/resumo_tecnico_censo_educacao_superior_2010.pdf>. Acesso em: 15 out. 2015.

CAPOZZOLO, A. A. et al. Experiência, produção de conhecimento e formação em saúde. Interface Comum. Saúde Educ., Botucatu, v. 17, n. 45, p. 357-370, abr./jun., 2013. Disponível em: <http://www.scielo. br/pdf/icse/v17 n45/09.pdf>. Acesso em: 18 jan. 2015.

DIAS, H. S. A.; LIMA, L. D.; TEIXEIRA, M. A trajetória da política nacional de reorientação da formação profissional em saúde no SUS. Ciênc. Saúde Coletiva, Rio de Janeiro, v. 18, n. 6, p. 1613-1624, 2013. Disponível em: <http://www.scielosp.org/pdf/csc/v18n6/13.pdf>. Acesso em: 2 jul. 2015.

FINKLER, M.; CAETANO, J. C.; RAMOS, F. R. S. Ética e valores na formação profissional em saúde: um estudo de caso. Ciênc. Saúde Coletiva, Rio de Janeiro, v. 18, n. 10, p. 3033-3042, 2013. Disponível em: <http:// www.scielo.br/pdf/csc/v18n10/v18n10a28.pdf>. Acesso em: 2 jul. 2015. 
FONSECA, M. R. C. C. Uso de medicamentos na gravidez: uma abordagem farmacoepidemiológica. Dissertação (Mestrado) - Universidade Estadual de Campinas, Campinas, SP, 2012.

FRAGELLI, T. B. O.; SHIMIZU, H. E. Prospecções para desenvolvimento de políticas públicas de formação de profissionais de saúde a partir da análise do cenário brasileiro de competência. Physis: Revista de Saúde Coletiva, Rio de Janeiro, v. 23 n. 1, p. 197-208, 2013. Disponível em: <http://www.scielo.br/pdf/physis/v23n1/11.pdf>. Acesso em: 10 jan. 2015

GUIMARÃES, R. Desafios da pós-graduação em saúde humana no Brasil. Rev. Saúde Pública, São Paulo, v. 45, n. 1, p. 1-13, 2011. Disponível em: <http://www.revistas.usp.br/rsp/article/view/32924/35494>. Acesso em: 10 jan. 2015.

LIMBERGER, J. B. Metodologias ativas de ensino-aprendizagem para educação farmacêutica: um relato de experiência. Interface Comum. Saúde Educ., Botucatu, v. 17, n. 47, p. 969-975, out./dez., 2013. Disponível em: <http://www.scielo.br/pdf/icse/v17n47/20. pdf>. Acesso em: 10 jan. 2015.

MOREIRA, M. S. et al. Uso de psicofármacos em crianças e adolescentes. Revista da Universidade Vale do Rio Verde, Três Corações, v. 12, n. 2, p. 1013-1049, ago./dez., 2014.

OLIVEIRA, G. A. Uso de metodologias ativas em educação superior. In: CECY, C.; OLIVEIRA, G. A.; COSTA, E. Metodologias ativas: aplicações e vivências em educação farmacêutica. Brasília: Associação Brasileira de Ensino Farmacêutico e Bioquímico, 2010. p. 11-33.
PAGLIOSA, F. L.; DA RÓS, M. A. O relatório Flexner: para o bem e para o mal. Rev. Bras. Educ. Méd., Rio de Janeiro, v. 32, n. 4, p. 492-499, out./ dez., 2008. Disponível em: <http://www.scielo.br/pdf/rbem/v32n4/ v32n4a12.pdf>. Acesso em: 20 dez. 2015.

ROCHA, R.S. et al . Consumo de medicamentos, álcool e fumo na gestação e avaliação dos riscos teratogênicos. Rev. gaúch. enferm., Porto Alegre, v. 34, n.2, p.37-45, 2013.

RODRIGUES, J.; MANTOVANI, M. DE F. O docente de enfermagem e sua representação sobre a formação professional. Esc. Anna Nery., Rio de Janeiro, v. 11, n. 3, p. 494-499, set., 2007. Disponível em: <http://www. scielo.br/pdf/ean/v11n3/v11n3a15.pdf>. Acesso em: 10 jan. 2015.

SERIANO, K. N.; MUNIZ, V. R. C.; CARVALHO, M. E. I. M. Percepção de estudantes do curso de fisioterapia sobre sua formação profissional para atuação na atenção básica no Sistema Único de Saúde. Fisioterapia Pesq., São Paulo, v. 20, n. 3, p. 250-255, 2013. Disponível em: <http:// www.scielo.br/pdf/fp/v20n3/09.pdf>. Acesso em: 10 jan. 2015.

TEIXEIRA, C. F.S.; COELHO, M. T. A. D.; ROCHA, M. N. D. Bacharelado interdisciplinar: uma proposta inovadora na educação superior em saúde no Brasil. Ciência \& Saúde Coletiva, v.18, n.6, p.1635-1646, 2013.

VAIDERGORN, J. Cidadania e direitos humanos na formação universitária. Cad. CEDES, Campinas, v. 30, n. 81, p. 253-256, maio/ago., 2010. Disponível em: <http://www.scielo.br/pdf/ccedes/v30n81/a09v3081. pdf>. Acesso em: 10 jan. 2015.

Submetido em: $14 / 09 / 2016$

Aceito em: 18/05/2017 